\section{Reclaiming biology}

\section{Suresh I.S. Rattan}

The Triple Helix. Gene, Organism, and Environment.

by Richard Lewontin

Harvard University Press, Cambridge, MA.

136 pages, US\$27.50; UK£ 15.50

ISBN 0-674-00159-1

From time to time you come across a book that while you are reading it makes you think: 'If only I were its author!' Honestly, that is how I felt after reading this remarkable book by Richard Lewontin, a population geneticist at Harvard University. The Triple Helix is a plea and an attempt to free biology from the reductionist clamps of physics and chemistry. The book's major theme and message to scientists is that our understanding of living systems will never be complete if we continue to view genes, organisms and their environments as separate entities.

The first three chapters of Lewontin's essay are English translations of lectures he originally presented in the Lezioni Italiani in Milan, Italy. They were subsequently published in 1998. The chapters 'Gene and Organism', 'Organism and Environment' and 'Parts and Wholes, Causes and Effects' describe and analyse some of the most important relationships between those tightly interconnected items. The final chapter, 'Directions in the Study of Biology', is a manifesto to give biology its rightful status as a complete science of the same value as physics and mathematics, and it presents practical suggestions and approaches for future research.

First of all, Lewontin draws our attention to the powerful lock of Descartes' philosophy describing organisms as machines. This metaphor has certainly been useful as a starting point for the description and analysis of the living world, but it has hampered the further evolution of biological science for a long time. When dealing with metaphors in science, there is always the inherent danger of confusing the comparison with the real thing. Using the example of two important concepts in biology-development and adaptation-Lewontin exposes the limitations of Descartian philosophy when it comes to explaining the wide variations among organisms in terms of both their life histories and the effects they have on their environment. He harshly criticises biologists who believe that a complete organism and its life can be easily simulated simply by feeding its complete nucleotide sequence into a sufficiently powerful computer. For Lewontin, this is outright 'bad biology' because this approach to explaining the living world is limited and naïve. Indeed, a real organism is not merely a sequence of nucleotides or a collection of genes, but a dynamic living system within the complex context of its surrounding milieu. To strengthen this point, he gives a variety of examples from the plant and animal kingdoms where the apparently fixed genetic programmes of development, growth and differentiation can be easily proven to go beyond any rigid notions of genetic determinism.

When writing about adaptation, Lewontin acknowledges that 'Darwin's alienation of the outside from the inside was an absolutely essential step in the development of modern biology. Without it we would still be wallowing in the mire of an obscurantist holism [...].' But going further in his argument, he stresses that the time has come to reconsider the relationship between the outside and the inside, between organism and environment. Instead of agreeing with the prevalent notion of adaptation that sees organisms as merely fitting into an independent environment, Lewontin strongly argues in favour of the view that the environment is a continually re-constructed condition, which works upon an organism and is in return worked upon by the organism. He makes the correct distinction between the purely physical world outside the reach of living thingssuch as the rotation of the earth, the sequence of interglacial and glacial ages or the impact of volcanoes-and environment which, by definition, is something that surrounds something else. 'Just as there can be no organism without an environment, so there can be no environment without an organism.' However, the author is also cautious in not letting his ideas get mixed up with the Gaia hypothesis, which considers the totality of biosphere, atmosphere and geosphere as a living system that actively reacts to changes within itself. This kind of extreme holism, he says, has only little value as a contribution to the biological sciences as it is not able to define clear boundaries between important and critical influences and trivial and ineffective ones. 'Obscurantist holism is both fruitless and wrong as a description of the world.'

Lewontin wants us to accept the fact, as well as its consequences, that biological systems occupy a different region of the space of physical relations than do simpler physico-chemical systems.' To get any further in biological research, scientists must recognise and explain the internal heterogeneity within biological systems. Biochemistry and molecular biology have had great successes in demonstrating and explaining similarity in life forms. But these reductionist approaches are unable to explain why even genetically identical organisms differ from each other, why different individuals within the same species differ, or why different individuals, organs, tissues and cells live, age and die differently. Lewontin also advocates moving biology from the present DNA-focused framework to the realm of gene products functioning within an environment that is being constantly created and altered by biological systems. Only then can biology attain its rightfully independent existence and its own identity as a research field.

The author is at the Danish Centre for Molecular Gerontology at the University of Aarhus, Denmark.

E-mail: rattan@imsb.au.dk

DOI: 10.1093/embo-reports/kvd113 